\title{
MiRNAs link Metabolic Reprogramming to Oncogenesis
}

\author{
Maria Hatziapostolou ${ }^{1-3^{*}}$, Christos Polytarchou ${ }^{1-3^{*}} \&$ Dimitrios Iliopoulos ${ }^{1-3 \#}$
}

${ }^{1}$ Center for Systems Biomedicine, ${ }^{2}$ Division of Digestive Diseases, ${ }^{3}$ Institute for Molecular Medicine, David Geffen School of Medicine, University of California Los Angeles, Los Angeles, $\mathrm{CA}$

*These authors have equally contributed.

\#Corresponding author: Dimitrios Iliopoulos, Ph.D., Center Systems Biomedicine, Division of Digestive Diseases, David Geffen School of Medicine, University of California at Los Angeles, 650 Charles E Young Dr., CHS 44-133, Los Angeles, CA 90095-7278. Tel: 310-825-8856; Email: diliopoulos@mednet.ucla.edu; Phone: 310-825-8856

This is not the final published version. Please see:

Hatziapostolou M, Polytarchou C, lliopoulos D. miRNAs link metabolic reprogramming to oncogenesis. Trends Endocrinol. Metab. 2013 Jul;24(7):361-73. 


\begin{abstract}
The most profound biochemical phenotype of cancer cells is their ability to metabolize glucose to lactate, even under aerobic conditions. This alternative metabolic circuitry is sufficient to support the biosynthetic and energy requirements for cancer cell proliferation and metastasis. Alterations in oncogenes and tumor suppressor genes are involved in the metabolic switch of cancer cells to aerobic glycolysis, increased glutaminolysis and fatty acid biosynthesis. MiRNAs mediate finetuning of genes involved directly or indirectly in cancer metabolism. In this review, we discuss the regulatory role of miRNAs on enzymes, signaling pathways and transcription factors involved in glucose and lipid metabolism. We further consider the therapeutic potential of metabolism-related miRNAs in cancer.
\end{abstract}

Keywords: miRNAs, metabolism, cancer, therapy

\title{
Highlights:
}

Metabolic reprogramming is a central hallmark of oncogenesis.

Metabolic pathway alterations in cancer are tightly regulated by microRNAs.

MicroRNAs regulating metabolic pathways are frequently silenced or overexpressed in cancer. MicroRNAs targeting the metabolic reprogramming cascade possess value for cancer therapy. 


\section{Metabolic reprogramming in cancer}

Cancer is a disease where cells have lost their normal checks on cell proliferation. Intrinsic and extrinsic molecular mechanisms converge to alter core cellular metabolism and provide support for the three basic needs of proliferating cells: rapid ATP generation to maintain energy status; increased biosynthesis of macromolecules; and maintenance of appropriate redox status [1]. To meet these needs, cancer cells often display fundamental changes in pathways of energy metabolism and nutrient uptake. Similar alterations are also observed in rapidly proliferating normal cells, representing responses to physiological growth signals [2, 3].

In comparison to normal cells, malignant transformation is associated with excessive glucose uptake, aerobic glycolysis, glutaminolysis, altered lipid metabolism, de novo fatty acid synthesis and increased generation of reactive oxygen species (ROS) (Figure 1). These bioenergetics and metabolic features allow cancer cells to proliferate and survive under adverse conditions such as hypoxia, and enable their progression, invasiveness, and subsequent distant metastasis [4].

The best characterized metabolic phenotype that distinguishes cancer from normal cells is the aerobic glycolysis, also termed the Warburg effect (Box 1). The fundamental finding of Warburg's studies was that cancer cells metabolize glucose to lactate under aerobic conditions, despite the fact that this metabolic pathway is much less energy efficient when compared to oxidative phosphorylation. The Warburg phenomenon has been observed across several tumor types and is often associated with a high rate of glucose uptake [5]. However, since these alterations are also observed in the proliferating normal cells it is not clear whether this metabolic profile is specific to cancer or just cell proliferation. Moreover, the Warburg effect alone cannot explain all the metabolic alterations that are necessary for cell growth requirements [6]. Instead, the importance of other nutrients in fueling cell growth, such as glutamine, has gained much attention the recent years [7]. The metabolic interactions between tumor and stroma add more complexity to the understanding of metabolic reprogramming of cancer. Tumors with the same genetic lesions have different metabolic profiles depending on the tissue they arise in [8], suggesting that 
the tissue microenvironment strongly affects the metabolic activity of cancer cells. Another mechanism that is not explained by the Warburg effect and still remains unclear is how cancer cells maintain the balance between enhanced glycolytic activity and the need for antioxidant production. ROS can directly suppress aerobic glycolysis, through inhibition of the glycolytic enzyme pyruvate kinase (PKM2), and induce the production of NADPH for anti-oxidant synthesis by allowing the accumulation of glycolytic intermediates [9]. In conclusion, although the Warburg phenomenon has become synonymous with the hallmark designation attributed to altered cancer metabolism, still remains unclear whether it plays a causal role in cancer or it is just an epiphenomenon.

\section{MiRNAs and Cancer}

MicroRNAs (miRNAs) are endogenous small non-coding RNAs, 18 to 25 nucleotides in length, which regulate gene expression [10]. The mechanism of miRNA biogenesis is described in Box 2. MiRNA-mediated regulation of gene expression may take place either through mRNA degradation or inhibition of translation. MiRNAs bind to the 3'-untranslated region (3'-UTR) of the target mRNA through imperfect base-pairing, thus are able to regulate a large number of genes simultaneously [11-13]. Therefore, miRNAs act as master gene regulators, similar to transcription factors and the two may cooperate and ultimately determine gene expression patterns in the cell $[14,15]$.

MiRNAs are involved in a number of biological processes, such as development. differentiation, proliferation, apoptosis or pluripotency $[10,16]$. Recent studies have shown that miRNAs control different aspects of energy metabolism including insulin production and signaling, glucose transport and metabolism, cholesterol and lipid homeostasis and amino-acid biogenesis $[17,18]$. MiRNAs regulate cell metabolic processes either directly by targeting key molecules of metabolic pathways (transporters, enzymes and kinases) or indirectly by modulating the expression of important transcription factors [16-18]. 
The full spectrum of miRNAs expressed in a specific cell type (the miRNAome) varies between normal and pathologic tissues and specific signatures of deregulated miRNAs harbor diagnostic and prognostic implications $[16,17]$. Deregulation of miRNA expression is involved in the initiation and progression of tumorigenesis and has been investigated in almost all types of human cancer [19]. Some miRNAs act mainly as tumor suppressors while others have a wellestablished role as oncogenes, depending upon their target genes. Multiple studies have revealed that the altered metabolic pathways in cancers are tightly regulated by miRNAs. The downstream targets of a number of miRNAs are directly or indirectly connected to metabolic regulation [18, 20]. In this review, we discuss the regulatory role of miRNAs on essential cancer metabolism molecular mechanisms.

\section{MiRNAs and Metabolic Reprogramming}

Regulation of glucose uptake receptors by miRNAs

Glucose transport across the plasma membrane of eukaryotic cells is mediated by two different types of membrane-associated carrier proteins, the $\mathrm{Na}^{+}$-coupled glucose transporters (SGLT) and glucose transporter facilitators (GLUT) (Figure 1). The SGLT family members function as sugar transporters (SGLT1 and SGLT2) or sensors (SGLT3) [21]. Eleven out of the 14 members of the GLUT family in humans facilitate glucose transport and exhibit differential regulation, tissuespecific expression and substrate specificity. The levels of GLUT1, GLUT2 and GLUT3 are found elevated in most malignant tissues, while the mRNA of GLUT4 and GLUT5 are below sensitivity [22]. Presumably, the deregulation of GLUTs may increase glucose uptake, satisfy the high glucose requirements and accelerate metabolism in cancer cells.

Among the different mechanisms regulating GLUTs, miRNAs may regulate glucose uptake via affecting GLUTs expression or indirectly through effects on other regulatory mechanisms (Table 1). MiR-195-5p, which is downregulated in bladder cancer, has been identified as a direct regulator of GLUT3 [23]. A protein with glucose transporter function, SLC45A3, is directly regulated by miR-32 [24]. GLUT4 expression is indirectly upregulated by miR-223 and 
downregulated by miR-133 $[25,26]$. Other examples of indirect regulation of glucose transport include miR-23a, which regulates SMAD4 and subsequently GLUT4 translocation [27] and miR21, which affects GLUT4 translocation in adipocytes [28]. However, the direct links between miRNA deregulation and glucose transport in cancer are largely unknown.

\section{Functions of miRNAs in glycolysis}

Recent studies have emphasized the miRNA regulation of the irreversible steps in glycolysis (Table 1). Hexokinases catalyze the first and irreversible step of glucose metabolism, the ATPdependent phosphorylation of glucose to yield glucose-6-phosphate (Figure 1) [29]. Hexokinase 2 (HK2) is overexpressed in tumors and contributes to aerobic glycolysis. Thus, it is characterized as a pivotal player in the Warburg effect and an emerging target for cancer metabolism therapeutics [30, 31]. MiR-143 inhibits HK2 expression in head and neck squamous cell carcinoma (HNSCC) cell lines. In accord, miR-143 inversely correlates with HK2 expression in HNSCC and lung tumors [32, 33]. Similarly, targeting of HK2 by miR-143 affects glucose metabolism in colon cancer cells [34]. Importantly, the 5q-syndrome a common subtype of the Myelodysplastic syndrome, is defined by an isolated interstitial deletion of chromosome $5 q$, where the MIR-143 gene resides [35]. This locus is often deleted in other malignancies [36], while miR143 has also been found down-regulated in a number of cancers [37, 38]. The miRNA-dependent regulation of hexokinase expression is not limited to HK2 as miR-138 targets HK1 [32]. Other important intermediate steps in the glycolysis pathway may be regulated by or regulate microRNAs. Aldolase A is a direct target of miR-122 in liver cells [39]. Phosphoglucose isomerase (PGI) has been associated with invasion and metastasis of cancer cells. PGI regulates the expression of the miR-200 family of microRNAs and subsequently the Epithelial-Mesenchymal Transition (EMT) in breast cancer cells [40].

Cancer cells re-express the embryonic isoform of pyruvate kinase (PK), PKM2, which dephosphorylates phosphoenolpyruvate (PEP) to pyruvate (Figure 1). PKM2 provides a metabolic advantage in that it allows the tumor cells to use phosphometabolites upstream of 
pyruvate as precursors for the synthesis of amino acids, nucleic acids and lipids [41, 42]. MiR326 has been shown to target PKM2 and suppress cell growth. As a result, in glioblastoma cell lines, the upregulation of PKM2 correlates with low levels of miR-326 [43]. Likewise, miR-122 targets PKM2 and inhibits hepatocellular carcinoma (HCC) proliferation. Significantly, the increased miR-122 promoter methylation in $\mathrm{HCC}$ inhibits its expression and relieves PKM2 suppression [44]. PKM2 overexpression in tongue SCC has been associated with the downregulation of miR-133a and miR-133b [45]. A set of microRNAs, deregulated in colorectal cancer, miR-124, miR-137 and miR-340 are proposed to regulate the switch of PKM gene expression from PKM2 to PKM1 [46]. Under hypoxic conditions, miR-210 represses ISCU1/2 and thus, decreases the activity of proteins controlling mitochondrial metabolism, including Complex I and aconitase [47]. Hence, miR-210 represses mitochondrial respiration and might indirectly facilitate aerobic glycolysis in cancer.

\section{MiRNAs involved in lactate metabolism}

In normal cells, when oxygen is available, pyruvate undergoes oxidative phosphorylation in mitochondria, through the tricarboxylic acid (TCA) cycle. When oxygen levels are low, pyruvate is converted to lactate in the cytoplasm by lactate dehydrogenase (LDH) (Figure 1). LDHB is a target of miR-375 which is downregulated in maxillary sinus and esophageal SCC (Table 1). This contributes to the increased levels of LDHB and correlates with increased tumor aggressiveness $[48,49]$.

Most of the lactate is secreted and can be taken up by the liver where it is converted into glucose and recycled to the bloodstream and back to the tumors. The ability of cells to secrete lactate depends on the monocarboxylate transporters (MCTs) (Figure 1). MCT1 is targeted by miR-29a, miR-29b and miR-124 (Table 1) [50]. During the progression of malignant melanoma, the highly expressed protein basigin (Bsg) interacts with MCT1 and 4. Let-7b has been shown to target Bsg and inhibit the invasiveness of melanoma cells, potentially through the disruption of this interaction (Table 1) [51]. 


\section{Glutamine Metabolism}

Apart from glucose, cancer cells exhibit increased glutamine intake and glutamine metabolism (glutaminolysis). This adaptive accelerated glutamine metabolism by cancer cells seems to provide substrates for increased lipogenesis and nucleic acid biosynthesis that are critical to the proliferative phenotype of the cancer cell. It has been demonstrated that cell transformation stimulates glutaminolysis and that many cancer cells are tightly dependent on this amino acid [52, 53].

Cancer cells are known to overexpress mitochondrial phosphate dependent and phosphate independent glutaminase, the enzyme that catalyzes the degradation of glutamine to glutamate and ammonia [54]. Glutamate can be converted directly into $\mathrm{GsH}$, by the enzyme glutathione cysteine ligase $(\mathrm{GCl})$, one of the most abundant antioxidants in mammalian cells important in controlling the redox state of all subcellular compartments [55]. Glutamate can also further oxidized to $\alpha$-ketoglutarate and enter the TCA cycle to produce ATP. It has been documented that the ammonia produced following glutaminolysis stimulates autophagy, suggesting that when glucose-depleted cells become more dependent on glutamine via glutaminase and glutamate dehydrogenase to produce $\alpha$-ketoglutarate, the excess ammonia triggers autophagy to provide sufficient energy to survive a period of glucose deprivation [56]. One of the major regulators of glutaminolysis is MYC, further supporting the concept that MYC promotes not only cell proliferation but also the generation of macromolecules and antioxidants required for growth. In the same line, the suppression of $M I R-23 A / B$ by MYC enhances mitochondrial glutaminase expression and glutamine metabolism [53].

\section{MiRNA regulation of insulin secretion and signaling}

In response to increased nutrient levels in the blood, pancreatic $\beta$-cells synthesize and secrete insulin. The effects of insulin secretion include glucose uptake in muscles and adipocytes, inhibition of glucose production in the liver and increased storage of nutrients in forms of fat, 
glycogen and protein. MicroRNAs have been implicated in insulin secretion regulation through effects on pancreatic development and insulin exocytosis. MiR-375 and miR-124a decrease insulin exocytosis through the repression of myotrophin [57, 58]. Additionally, miR-9 regulate insulin secretion through inhibition of the transcription factor one cut homeobox 2 [59].

Other miRNAs act in target tissues to regulate responses to insulin and glucose homeostasis. The let-7 tumor suppressor microRNAs are known for their regulation of oncogenes, while the RNA-binding proteins Lin28a/b promote malignancy by blocking let-7 biogenesis. In studies using transgenic mice, it has been demonstrated that the Lin28/let-7 pathway is a central regulator of mammalian glucose metabolism. Both Lin28a and LIN28B promoted an insulin-sensitized state that resisted high fat diet-induced diabetes, whereas muscle-specific loss of Lin28a and overexpression of let-7 resulted in insulin resistance and impaired glucose tolerance. These phenomena occurred in part through let-7-mediated repression of multiple components of the insulin-PI3K-mTOR pathway [60]. Furthermore, it was recently shown that Lin28 restores glucose metabolism in obese adipocyte stem cells through repression of let-7 expression [61]. MiR-29a and miR-29b, have been linked to insulin resistance, through the down-regulation of proteins that promote insulin signaling like caveolin 2 and phosphatidylinositol 3-kinase (PI3K) regulatory subunit- $\alpha[62,63]$. The inhibition of insulin receptor substrate-1 (IRS1) by miR-126 also promotes insulin resistance [64], while miR-33a and miR-33b affect insulin signaling and glucose regulation by targeting IRS2, SIRT6 and AMPKa1 [65]. Additionally, miR-33a may regulate Pim-1, a kinase that possesses overlapping functions with Akt [66]. In this context, it has been demonstrated that miR-33a may be an efficient strategy for microRNA replacement therapy [67]. IRS-2 is a target of miR-7-5p in melanoma cells. MiR-7-5p is downregulated in metastatic melanoma-derived cell lines and regulates melanoma cell migration and invasion through upregulation of IRS-2 and induction of Akt [68].

Obesity is an established risk and progression factor for many cancers. In obesity models, several miRNAs are overexpressed and exert regulatory effects on insulin signaling and glucose homeostasis. MiR-103, miR-107 and miR-143 are overexpressed and reduce insulin sensitivity 
$[69,70]$. Protein tyrosine phosphatase 1B (PTP1B), a target of miR-122, inhibits hepatic insulin signaling by dephosphorylating insulin receptor and IRS. In high-fat-diet-fed mice and hepatocyte models with insulin resistance, the expression of miR-122 is downregulated [71].

\section{MiRNAs and Lipid Metabolism}

Lipids form a diverse group of water-insoluble molecules and include triglycerides, phospholipids, sterols and sphingolipids. Triglycerides are mainly used for energy storage while phospholipids, together with sterols and sphingolipids, represent the major structural components of biological membranes. Lipids can also act as signaling molecules, functioning as second messengers (e.g. sphingolipids) and as hormones (e.g. steroid hormones) [72]. Lipids such as cholesterol and fatty acids are taken up in the diet and are synthesized de novo, predominantly in the liver. Regulation of the biosynthesis of cholesterol, fatty acids and phospholipids is mediated by transcription factors such as sterol regulatory element binding proteins (SREBPs) [73]. A major transcription factor of the liver that regulates lipid homeostasis and controls the expression of $12 \%$ of the genes expressed is hepatocyte nuclear factor a (HNF4a) [74]. Interestingly, adult liver-specific knockout mice of the HNF4A gene exhibit fatty liver and greater than $70 \%$ mortality by 8 weeks of age [75]. A more broad effect of HNF4a on metabolism is reflected on the finding that mutations on the HNF4A gene contribute to several forms of maturity-onset diabetes in children [76].

Changes in lipid metabolism can affect numerous cellular processes, including proliferation, differentiation and cell motility. There is increasing evidence that cancer cells show specific alterations in different aspects of lipid metabolism. One characteristic is that irrespective of the concentration of extracellular lipids, fatty acids are mainly synthesized de novo [72]. Another characteristic is that some tumor types, instead of exhibiting a high rate of glucose uptake they exhibit increased dependence on lipid oxidation as their main energy source. One such example is prostate cancer, which generally displays a low rate of glucose utilization, showing increased uptake of fatty acids and overexpression of some $\beta$-oxidation enzymes $[77,78]$. The increased availability of lipids in cancer cells contributes to several aspects of tumor biology such as cell 
growth and proliferation, survival under oxidative and energy stress, chemoresistance, support of a high-glycolytic rate by promoting redox balance and stimulation of signaling pathways that lead to invasion and metastasis $[72,79]$.

MiR-122 was the first miRNA to be linked to metabolic control. It is expressed primarily in the liver and was initially shown to affect hepatic cholesterol and lipid metabolism [80]. Antisense targeting of miR-122 in the whole animal results in a vast reduction in plasma cholesterol by affecting the expression of genes involved in cholesterol biosynthesis [81], and inducing fatty acid $\beta$-oxidation [82]. However, the genes affected by miR-122 in the liver and are involved in cholesterol and lipid metabolism, do not seem to be direct targets of miR-122 [81]. Interestingly, miR-122 was successfully targeted by antisense inhibitors using locked nucleic acid (LNA) chemistry in non-human primates, resulting in lowered circulating cholesterol [83]. Regarding cancer, deletion of miR-122 in mice causes several key phenotypes of chronic human liver diseases and eventually liver cancer $[84,85]$. This lack of mechanistic understanding of miR-122 and the carcinogenic effect of miR-122 suppression raised questions about the development of miR-122 antisense technologies as therapeutic approaches.

Several recent studies have reported $\mathrm{miR}-33 \mathrm{a} / \mathrm{b}$ as a regulator of cholesterol/lipid metabolism and energy homeostasis. MIR-33A/B embeds within intron sequences of the human SREBF genes and controls the levels of ATP-binding cassette transporter ABCA1, a cholesterol efflux pump $[86,87]$. Thus, Srebp and miR-33 may cooperate to regulate cell proliferation and cell cycle progression [88]. MiR-33a/b also acts in the lipid homeostasis pathway by controlling the expression of fatty acid $\beta$-oxidation genes and energy homeostasis regulators like AMPK and SIRT6 [65].

There's evidence that miRNAs are involved in the differentiation of adipocytes and the development of obesity $[89,90]$. MiR-335 is up-regulated in the white adipose tissue of obese mice and is associated with elevated hepatic triglycerides and cholesterol [90]. Additionally, miR370 acting via miR-122 may accumulate hepatic triglycerides by modulating initially the 
expression of SREBP-1c, DGAT2, and Cpt1 $\alpha$ and, subsequently, the expression of other genes that affect lipid metabolism [91].

It was recently demonstrated that miR-24 and miR-629 suppress directly HNF4a expression inducing hepatocellular cancer initiation and growth. Furthermore, we have shown that miR-24 and miR-629 are upregulated in HCC and their expression is mediated by STAT3. We have further demonstrated that HNF4a controls the expression of miR-124, a miRNA suppressed in HCC. Our findings suggest that transient inhibition of HNF4a initiates hepatocellular transformation through a feedback loop circuit that consists of miR-124, miR-24, miR-629 and STAT3. Once this circuit is activated it maintains suppression of HNF4a and sustains oncogenesis [15].

\section{MiRNA regulation of signaling pathways}

The fact that a plethora of the predominant mutations observed in cancer also regulate cell metabolism led to the theory that oncogene and tumor suppressor networks influence the metabolic shift in cancer. Accordingly, the interrelation between deregulated microRNAs and imbalanced signaling pathways largely contributes to abnormal cell metabolism and carcinogenesis (Table 2). Major factors and pathways involved in metabolic reprogramming include HIF1A, MYC, AKT, AMPK, and p53 (Figure 2).

HIF1 and MYC transcription factors: The hypoxia-inducible factor (HIF) complexes are transcription factors regulating gene expression upon oxygen deprivation. HIF1 $\alpha$ or HIF2 $\alpha$ subunits are stabilized upon exposure to hypoxia and form heterodimers of the HIF1 $\beta$. These two transcription factors increase the cell capacity to carry out glycolysis, through the activation of genes encoding glucose transporters and most glycolytic enzymes, and reinforce the glycolytic phenotype through activation of the pyruvate dehydrogenase kinases (PDKs) which reduce the flow of pyruvate into the TCA cycle (Figure 2) [1]. MiR-199a downregulation upon oxygen deprivation is required for the rapid upregulation of its target, HIF1a [92]. In chronic lymphocytic 
leukemia (CLL), the stabilization of HIF1 under normoxia is mediated by miR-92-1. MiR-92-1 targets the von Hippel-Lindau (VHL) tumor suppressor [93], an E3 ubiquitin ligase which marks HIF1a for degradation in the presence of oxygen. Under hypoxia, miR-424 upregulation in endothelial cells stabilizes HIF1a through the targeting of cullin 2, a scaffolding protein critical to the assembly of ubiquitin ligase system [94]. Glycerol-3-phosphate dehydrogenase 1-like (GPD1L), an inhibitor of HIF-1 $\alpha$ stability is a direct target of miR-210. Importantly, miR-210, a transcriptional target of HIF-1 $\alpha$ is overexpressed in multiple cancers and reinforces HIF-1 $\alpha$ activity [95]. The oncogenic transcription factor MYC collaborates with HIF in the activation of several glucose transporters, glycolytic enzymes, LDHA and PDK1. In parallel, MYC regulates glutamine metabolism and mitochondrial function through the activation of genes involved in mitochondrial biogenesis $[4,52]$. MYC increases glutamine uptake by directly inducing the expression of the glutamine transporters sIC5A1 and sIC7A1 (also known as CAT1) [53]. MiR-33b has been identified as a negative regulator of $\mathrm{c}-\mathrm{MYC}$. Thus, in medulloblastomas loss of the $17 \mathrm{p} 11.2$ genomic locus, where MIR-133b resides, results in c-Myc overproduction [96]. MYC directly upregulates a pro-tumorigenic group of miRNAs known as the miR-17-92 cluster (Figure 2) [97]. This cluster leads to inhibition of tumor suppressor PTEN, an antagonist of PI3K/Akt/mTOR pathway which plays important roles in facilitating aerobic glycolysis in cancer cells [98].

The PISK/AKT/mTOR pathway: The AKT pathway, commonly activated in human cancers, is a key regulator of survival and apoptosis, cell cycle and growth, protein synthesis and glucose metabolism [99]. AKT, which lies downstream of PI3K, stimulates glycolysis by increasing the expression and membrane translocation of glucose transporters and by phosphorylating key glycolytic enzymes, such as hexokinase $[100,101]$ (Figure 2). Through the inhibition of forkhead box subfamily O (FOXO) transcription factors, AKT increases the glycolytic capacity and lipid genesis [102, 103]. In addition, AKT strongly stimulates mTOR by phosphorylating and inhibiting its negative regulator tuberous sclerosis 2 (TSC2). Activated mTOR stimulates protein and lipid biosynthesis and cell growth in response to sufficient nutrient and energy conditions [103]. Finally, 
sustained activation of the PI3K/AKT/mTOR pathway in cancer regulates metabolism partly through HIF-1a induction under normoxic conditions (Figure 2) [1, 99]. MiR-126, frequently lost in colorectal cancers, impedes tumor cell growth by targeting the p85b subunit of PI3K [104]. MiR21, a microRNA increased in multiple cancers, activates AKT through the inhibition of PTEN and induces the tumor cell migration, proliferation and invasiveness [105]. It has been demonstrated that AKT2, one of the three isoforms of AKT, under hypoxic conditions regulates miR-21 and promotes resistance to hypoxia through activation of all isoforms [106]. It was recently shown that AKT isoforms differentially regulate microRNA expression. In specific, through the downregulation of miR-200 family of microRNAs, AKT signals may govern EMT and cancer stem cell-like properties [107]. On the other hand, miR-143 upregulation in the liver of obese mice results in downregulation of oxysterol-binding-protein-related protein 8 and thus impaired ability of insulin to induce AKT activation [70]. In liver cancer the upregulation of miR-221 negatively correlates to the expression of DNA damage-inducible transcript 4 (DDIT4), a modulator of mTOR [108]. In addition, miR-100 was found to target mTOR and its downregulation in ovarian cancer cell lines enhanced mTOR signaling [109]. MiR-199a-3p, downregulated in several human malignancies, inversely correlates with its target mTOR in hepatocellular carcinomas [110].

AMP-activated protein kinase: The AMPK pathway couples energy status to growth signals. It functions as a metabolic checkpoint, regulating the cellular responses to energy availability [111]. LKB1 a kinase that lies upstream of AMPK, in the presence of AMP, when intracellular levels of ATP are low, phosphorylates and activates AMPK (Figure 2) [112]. Thus, during periods of energetic stress, AMPK becomes activated in response to an increased AMP/ATP ratio, and is responsible for shifting cells to an oxidative metabolic phenotype and inhibiting cell proliferation. In tumor cells uncoupling the fuel signals from growth signals, allows them to divide under abnormal nutrient conditions. In fact, many cancer cells exhibit a loss of appropriate AMPK signaling which may also contribute to their glycolytic phenotype [1, 111]. Interestingly, miR-451 promotes glioma cell adaptation to metabolic stress through suppression of the LKB-1-associated 
protein CAB39 and indirect activation of mTOR signaling [113]. Recently, miR-195 has been found to also target CAB39 and regulate mTOR [114].

The p53 pathway: Tumor suppressor p53, best known for its functions in the DNA damage response and apoptosis, it is also an important regulator of metabolism. p53 activates the expression of HK2 [115], TP53-induced glycolysis and apoptosis regulator (TIGAR) [116], PTEN [117] and SCO2 [118]. TIGAR decreases the levels of the glycolytic activator fructose-2,6bisphosphate and PTEN inhibits the PI3K pathway, and collectively suppress the glycolytic pathway, while SCO2 increases mitochondrial metabolism (Figure 2). Hence, loss or suppression of p53, an event common in cancers, might function as a major force behind the acquisition of the glycolytic phenotype. Several studies have identified miRNAs as regulators of p53 activity as well as its downstream effectors (Table 2). The 3'-UTR of p53 mRNA contains a conserved response element for miR-125b [119]. MiR-504 acts as a negative regulator of human p53, decreases p53 protein levels and promotes tumorigenicity [120]. A library screen identified a group of microRNAs regulating p53 activity. Among them, miR-30d downregulate p53 protein levels and inhibit p53transcriptionally activated genes [121]. A screen for microRNAs against p53 activity, reported to be deregulated in human tumors, revealed the positive regulation of p53 by the miR-29 family members. This effect was attributed to direct suppression of the p85 regulatory subunit of PI3K and CDC42, a Rho family GTPase, both of which negatively regulate p53 [122]. The oncogenic role of miR-122 loss in the liver has been attributed to the indirect regulation of p53. In specific, by modulating cyclin G1, miR-122 influences p53 protein stability and transcriptional activity [123]. MiR-25 and miR-32 are also indirect regulators of p53 by targeting directly Mdm2 and TSC1, which are negative regulators of the p53 and the mTOR pathway. MiR-25 and miR-32 induce accumulation of p53 and subsequently inhibition of glioblastoma cell growth [124]. MiR-7 has been found to target YY1, a p53 suppressor. Hence, downregulation of miR-7 in a subset of colorectal cancers correlates with repression of p53 [125]. In another subset of colorectal cancers miR-218 downregulation has been correlated with inhibition of $\mathrm{p53}$, through derepression of its 
target BMI1 [126]. Downstream of p53, a p53 response element in the promoter of miR-145 provides the link between this tumor suppressor miRNA and its direct target, c-Myc [127]. It has also been shown that under genetic stress, p53 may interact with the Drosha processing complex and thus enhance the post-transcriptional maturation of several miRNAs with growth-suppressive function, including miR-16-1, miR-143 and miR-145 [128]. The members of the pro-apoptotic miR34 family are expressed at very low levels in several types of cancers $[129,130]$ and have been characterized as direct transcriptional targets of p53 [131-133]. However their role as downstream effectors of p53 is currently under debate. A recent report investigating the role of miR-34 in the intact mouse showed that mir-34 knockouts remain healthy with no spontaneous tumors [134].

\section{Therapeutic Potential of Metabolism-Related MiRNAs}

\section{MiRNA Therapeutics in Cancer Metabolism}

The possibility that agents targeting cell metabolism could be effective across diverse cancer types has historical precedent. For example, antifolate drugs were developed before there was an understanding of how folic acid contributes to nucleic acids generation. Today, the antimetabolite class of nucleoside analogues - among them 5-fluorouracil and gemcitabine is widely used in the treatment of diverse human tumors [135]. Although these drugs are not considered 'targeted therapies', they have clear targets in metabolism and remain effective therapies for many human cancers. Considering the recent increase in our understanding of cancer metabolism the question arises: could metabolism be cancer's Achilles heel? Are there differences between normal and cancer cell metabolism that provide clinically relevant therapeutic windows? These questions have been addressed by recent recommendable reviews [6, 136, 137], and here we focus on the therapeutic potential of metabolism-related miRNAs.

It has been identified through gain- and loss-of-function studies that miRNA deregulation could have therapeutic effects by suppressing the growth of cancer cells without affecting the growth of normal cells [138]. These findings have enforced the development of miRNA-based therapeutics in the last few years. To overcome delivery challenges innate with small RNA 
therapeutics, chemical modifications, nanoparticles, liposomes, polymers are being exploited for effective delivery of miRNAs to targeted sites.

Different chemical modifications in antisense-miRNAs have been developed aiming to enhance the specificity and potency of these inhibitors [138]. The LNA modification increases the stability of antisense miRNAs, which could be delivered by intratumoral, intraperitoneal and intravenous injections. A Phase 2 trial of the LNA anti-miR-122 is being carried out in human subjects in Denmark [139]. In addition to the LNA technology, cholesterol-modified miRNAs (cholanti-miRs) exhibit improved pharmacokinetics and anti-tumor efficacy. For example, chol-antimiR-221 suppresses effectively liver tumor growth in vivo [140].

Regarding miRNA mimics, they are administered either directly by injection or indirectly through systemic adenoassociated viral (AAV) delivery [141]. It was recently demonstrated that systemic administration of miR-124 suppresses liver cancer growth in vivo, through suppression of the IL6/STAT3 inflammatory pathway [15]. Furthermore, AAV-delivery of miR-26a or miR-122 suppresses MYC-driven liver carcinogenesis in vivo without affecting normal hepatocytes [84, 142]. One recent study proposes the systemic delivery of miRNA mimics in complex with neutral lipid emulsion, showing therapeutic benefits in mouse models of lung cancer. Therapeutic delivery was demonstrated for the two well-characterized families of tumor suppressor miRNAs let-7 and miR-34: let-7 targets RAS and MYC oncogenes while miR-34 is directly transcribed by p53 [143].

\section{Metformin: From Diabetes to Cancer Therapy}

Links between cancer and metabolic disorders such as diabetes have long been suspected [144]. Metabolic disorders cause alterations in glucose metabolism and could be associated with increased cancer risk. As a result antidiabetic drugs such as metformin, which is currently taken by 100 million people worldwide, are being explored for anti-tumor activity [144-146]. Multiple epidemiological studies show that diabetic patients treated with metformin have reduced incidence of cancer and reduced cancer mortality [145]. In addition, metformin affects the progression and relapse of breast, prostate and lung cancer, when combined with suboptimal 
doses of standard chemotherapeutic agents [147-149]. Metformin activates AMPK that leads to suppression of mTOR and stimulation of the p53 axis, hence affecting metabolic and carcinogenic processes. The anticancer activity of metformin on different types of cancer suggests the existence of a broader mechanism of action for this drug. This was further supported by a recent study demonstrating that miRNA modulation underlies the anticancer metabolic actions of metformin [112]. Metformin-modulated miRNAs were predicted to impinge mainly on the energy metabolism and insulin signaling pathways. In addition, it was shown that metformin affects the mRNA levels of c-MYC, IRS-2 and HIF1a as well [146].

\section{Concluding remarks and future perspectives}

Over recent years, miRNAs have emerged as major players in the complex network of gene regulation and have been implicated in various aspects of human disease. The fact that miRNAs can be found circulating in the blood, either inside exosomes or as "free" molecules, not only points to their potential use as biomarkers, but also suggests that circulating miRNAs may be actively secreted from cells to act as signaling molecules that alter the gene expression output of distant target cells. The involvement of miRNAs in carcinogenesis has been well documented for almost a decade and scientists have roughly categorized those miRNAs to oncogenic and tumor suppressor miRNAs. For years now, cancer researchers have been seeking molecular mechanisms underlying the Warburg effect in an effort to model cancer metabolism and select target combinations for possible therapeutic intervention. The recent finding that miRNAs are important regulators of cell metabolism makes clear that it is particularly significant to complement these models with the function of miRNAs in cancer cells. This approach will provide new insight into which enzymes, miRNAs or their combination represent promising targets for cancer therapy. 
Table 1. Glucose metabolism-regulating microRNAs deregulated in cancer

\begin{tabular}{|c|c|c|c|}
\hline microRNA & Target & Up/Down & Disease \\
\hline \multicolumn{4}{|c|}{ Glucose uptake } \\
\hline miR-133 & GLUT4 & $=$ & $\begin{array}{l}\text { bladder cancer, pancreatic ductal adenocarcinoma, } \\
\text { oesophageal squamous cell carcinoma of the tongue, } \\
\text { hepatocellular carcinoma, lung carcinoma }\end{array}$ \\
\hline miR-223 & GLUT4 & $=$ & $\begin{array}{l}\text { chronic lymphocytic leukemia, osteosarcoma, } \\
\text { peripheral nerve sheath tumors, hepatocellular } \\
\text { carcinoma, acute lymphoblastic leukemia }\end{array}$ \\
\hline miR-32 & SLC45A3 & $=$ & $\begin{array}{l}\text { bronchial squamous cell carcinoma, } \\
\text { lung adenocarcinoma }\end{array}$ \\
\hline miR-195-5p & GLUT3 & $=$ & $\begin{array}{l}\text { bladder cancer, gastric cancer, colorectal cancer, } \\
\text { glioblastoma, adrenocortical carcinoma }\end{array}$ \\
\hline miR-23a & SMAD4 & - & $\begin{array}{l}\text { colorectal cancer, hepatocellular carcinoma, } \\
\text { pancreatic cancer, oral squamous cell carcinoma, } \\
\text { bladder cancer }\end{array}$ \\
\hline \multicolumn{4}{|l|}{ Glycolysis } \\
\hline miR-143 & Hexokinase 2 & $=$ & $\begin{array}{l}\text { esophageal squamous cell carcinoma, lung cancer, } \\
\text { colorectal cancer, cervical carcinoma, liposarcoma, } \\
\text { bladder cancer, osteosarcoma, gastric cancer }\end{array}$ \\
\hline miR-138 & Hexokinase 1 & $=$ & $\begin{array}{l}\text { nasopharyngeal carcinoma, hepatocellular carcinoma, } \\
\text { papillary thyroid carcinoma, tongue squamous cell } \\
\text { carcinoma, head and neck/oral cancer }\end{array}$ \\
\hline miR-122 & Aldolase A/ PKM2 & $=$ & hepatocellular carcinoma \\
\hline miR-326 & PKM2 & $=$ & glioblastoma, pituitary $\mathrm{GH}$ adenoma \\
\hline miR-133a/b & PKM2 & $=$ & see above \\
\hline $\operatorname{miR}-210$ & ISCU1/2 & - & $\begin{array}{l}\text { lung cancer, adrenocortical carcinoma, } \\
\text { clear-cell kidney cancer, pancreatic cancer, } \\
\text { clear cell renal cell carcinoma, breast cancer }\end{array}$ \\
\hline \multicolumn{4}{|c|}{ Lactate metabolism and secretion } \\
\hline miR-375 & LDHB & - & $\begin{array}{l}\text { maxillary sinus-esophageal squamous cell carcinoma, } \\
\text { laryngeal squamous cell carcinoma, nonsmall cell } \\
\text { lung cancer, rectal cancer, gastric cancer }\end{array}$ \\
\hline $\operatorname{miR}-29 a / b$ & MCT1 & $=$ & $\begin{array}{l}\text { B-cell lymphoma, acute myelogeneous leukemia, } \\
\text { hepatocellular carcinoma, cutaneous melanoma }\end{array}$ \\
\hline miR-124 & MCT1 & $=$ & $\begin{array}{l}\text { hepatocellular carcinoma, gastric cancer, } \\
\text { pancreatic cancer, colorectal cancer, cervical cancer, } \\
\text { haematological malignancies, medulloblastoma }\end{array}$ \\
\hline let-7b & Basigin & - & $\begin{array}{l}\text { breast cancer, colorectal cancer, ovarian serous } \\
\text { carcinoma, head and neck sauamous cell carcinoma }\end{array}$ \\
\hline
\end{tabular}


Table 2. MicroRNAs deregulated in cancer, targeting signals involved in metabolism.

\begin{tabular}{|c|c|c|c|}
\hline microRNA & Target & Up/Down & Disease \\
\hline \multicolumn{4}{|l|}{ HIF1 and MYC } \\
\hline miR-199a & HIF1A & $=$ & \multirow{2}{*}{$\begin{array}{l}\text { osteosarcoma, small cell cervical carcinoma, } \\
\text { testicular cancer, hepatocellular carcinoma, } \\
\text { ovarian cancer }\end{array}$} \\
\hline & & & \\
\hline miR-92-1 & VHL & $=$ & $\begin{array}{l}\text { chronic lymphocytic leukemia, } \\
\text { multiple myeloma, lung cancer }\end{array}$ \\
\hline $\operatorname{miR}-424$ & CULLIN1 & - & colorectal cancer \\
\hline miR-210 & GPD1L & $=$ & see Table 1. \\
\hline miR-429 & CMYC & $=$ & $\begin{array}{l}\text { renal cell carcinoma, gastric cancer, } \\
\text { nasopharyngeal carcinoma }\end{array}$ \\
\hline miR-135a & CMYC & $=$ & $\begin{array}{l}\text { renal cell carcinoma, gastric cancer, } \\
\text { glioma, Hodgkin lymphoma }\end{array}$ \\
\hline miR-33b & CMYC & $=$ & medulloblastoma \\
\hline miR-223 & CMYC & $=$ & see Table 1. \\
\hline \multicolumn{4}{|c|}{$\mathrm{PI3K} / \mathrm{AKT} / \mathrm{mTOR}$} \\
\hline miR-126 & PI3K & $=$ & \multirow{2}{*}{$\begin{array}{l}\text { colorectal cancer, lung cancer, pancreatic cancer, } \\
\text { malignant pleural mesothelioma, breast cancer, } \\
\text { gastric cancer, cervical cancer }\end{array}$} \\
\hline & & & \\
\hline miR-21 & PTEN & $=$ & \multirow{2}{*}{$\begin{array}{l}\text { breast cancer, glioblastoma, hepatocellular carcinoma, } \\
\text { chronic myelogeneous leukemia, cervical cancer, } \\
\text { stomach cancer, colorectal cancer, prostate cancer, } \\
\text { cholangiocarcinoma, lung cancer, esophageal cancer }\end{array}$} \\
\hline & & & \\
\hline miR-143 & ORP8 & $=$ & see Table 1. \\
\hline miR-100 & MTOR & $=$ & \multirow{2}{*}{$\begin{array}{l}\text { lung cancer, esophageal cancer, ovarian cancer, } \\
\text { head and neck squamous cell carcinoma, cervical } \\
\text { cancer, bladder cancer }\end{array}$} \\
\hline & & & \\
\hline miR-199a-3p & MTOR & $=$ & see above \\
\hline miR-223 & FOX01 & $=$ & see Table 1. \\
\hline \multicolumn{4}{|l|}{ LKB1/AMPK } \\
\hline miR-451 & CAB39 & $=$ & $\begin{array}{l}\text { pancreatic cancer, glioma, } \\
\text { head and neck squamous cell carcinoma }\end{array}$ \\
\hline miR-195 & CAB39 & $=$ & chronic lymphocytic leukemia, gastric cancer \\
\hline \multicolumn{4}{|l|}{ P53 } \\
\hline miR-125b & P53 & $=$ & $\begin{array}{l}\text { endometrial carcinoma, hepatocellular carcinoma, } \\
\text { thyroid cancer, acute lymphoblastic leukemia }\end{array}$ \\
\hline miR-30 & P53 & $=$ & $\begin{array}{l}\text { anaplastic thyroid carcinoma, medulloblastoma, } \\
\text { hepatitis B virus-associated hepatocellular carcinoma }\end{array}$ \\
\hline miR-122 & CYCLING1 & $=$ & see Table 1. \\
\hline miR-29 & $\mathrm{PI} 3 \mathrm{~K} / \mathrm{CDC} 42$ & 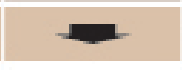 & see Table 1. \\
\hline miR-7 & YY1 & $=$ & breast cancer, gastric cancer, glioblastoma \\
\hline miR-218 & BMI1 & 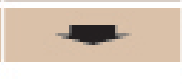 & $\begin{array}{l}\text { cervical cancer, gastric cancer, lymphoma, } \\
\text { bladder cancer, lung cancer, medulloblastoma }\end{array}$ \\
\hline
\end{tabular}




\section{Box 1 - The Warburg effect}

In the 1920s, Otto Warburg first proposed the theory that cancer cells exhibit atypical metabolic characteristics. Specifically, Warburg found that in contrast to normal cells cancer cells metabolize glucose into lactate under aerobic conditions [251, 252]. Normal cells, in the presence of oxygen, metabolize glucose to pyruvate which in turn is completely oxidized to carbon dioxide in mitochondria through oxidative phosphorylation (Ref). The metabolism of glucose to lactate is far less efficient, in terms of ATP generation per molecule of glucose, (2 ATPs) when compared to oxidative phosphorylation (36 ATPs). A possible explanation for this seemingly paradoxical phenomenon is the necessity for a cell to produce metabolic products that extend beyond the ATP. Acetyl-coA is necessary for fatty acid biosynthesis, glycolytic intermediates for non-essential amino acids and ribose for nucleotides $[2,253]$. The Warburg phenomenon has been supported by multiple studies in a variety of tumor types, and is now exploited in the clinic for diagnostic purposes. Fluorodeoxyglucose positron emission tomography imaging is used today for the detection of primary tumors and metastases of several types of cancer [254]. Emerging understanding on the molecular mechanisms responsible for the Warburg effect indicate that the hypoxic altered tumor microenvironment, activation of proto-oncogenes (c-MYC) and kinases (AKT, AMPK), activation and/or stabilization of transcription factors (HIF-1), as well as the inactivation of tumor suppressors (p53), induce the glycolytic phenotype of cancer cells [2]. 


\section{Box 2 - The canonical miRNA biogenesis pathway}

A canonical pathway driven by RNAse III enzymes generates the majority of animal miRNAs. MiRNA genes are either independent genes (intergenic) or portions of introns of protein-coding genes (intragenic) [255]. RNA polymerase II transcribes miRNA genes, generating long primary transcripts (pri-miRNAs). Subsequently, the process to yield mature miRNAs involves two consecutive cleavages by two RNase-III enzymes and the companion of double-stranded RNAbinding proteins. In the nucleus, the single strand-double strand junction of the pri-miRNA hairpin is recognized by DGCR8, which positions the catalytic site of the RNase III enzyme Drosha. This cleavage yields hairpin precursors (pre-miRNAs), consisting of approximately 70 nucleotides, that are exported to the cytoplasm $[256,257]$. The pre-miRNA hairpins are cleaved toward the terminal loop by the RNase III enzyme Dicer. This process gives rise to unstable, miRNA/miRNA duplex structures of $19-25$ nucleotides length $[258,259]$. The miRNA/miRNA* duplexes are loaded into miRNA-class Argonaute effectors (in mammals, Ago1-4). One of the duplex strands is preferentially retained in Ago to form the functional RNA-induced silencing complex (RISC) [260, 261]. The RISC-miRNA assembly is then guided to specific target sequences in mRNAs. The initial recognition of mRNAs by the RISC-miRNA complex is driven primarily by Watson-Crick base-pairing of nucleotides 2 to 8 in the mature miRNA (seed sequence) with specific mRNA target sequences chiefly located in the 3'-untranslated region (3'-UTR). 


\section{Figures}

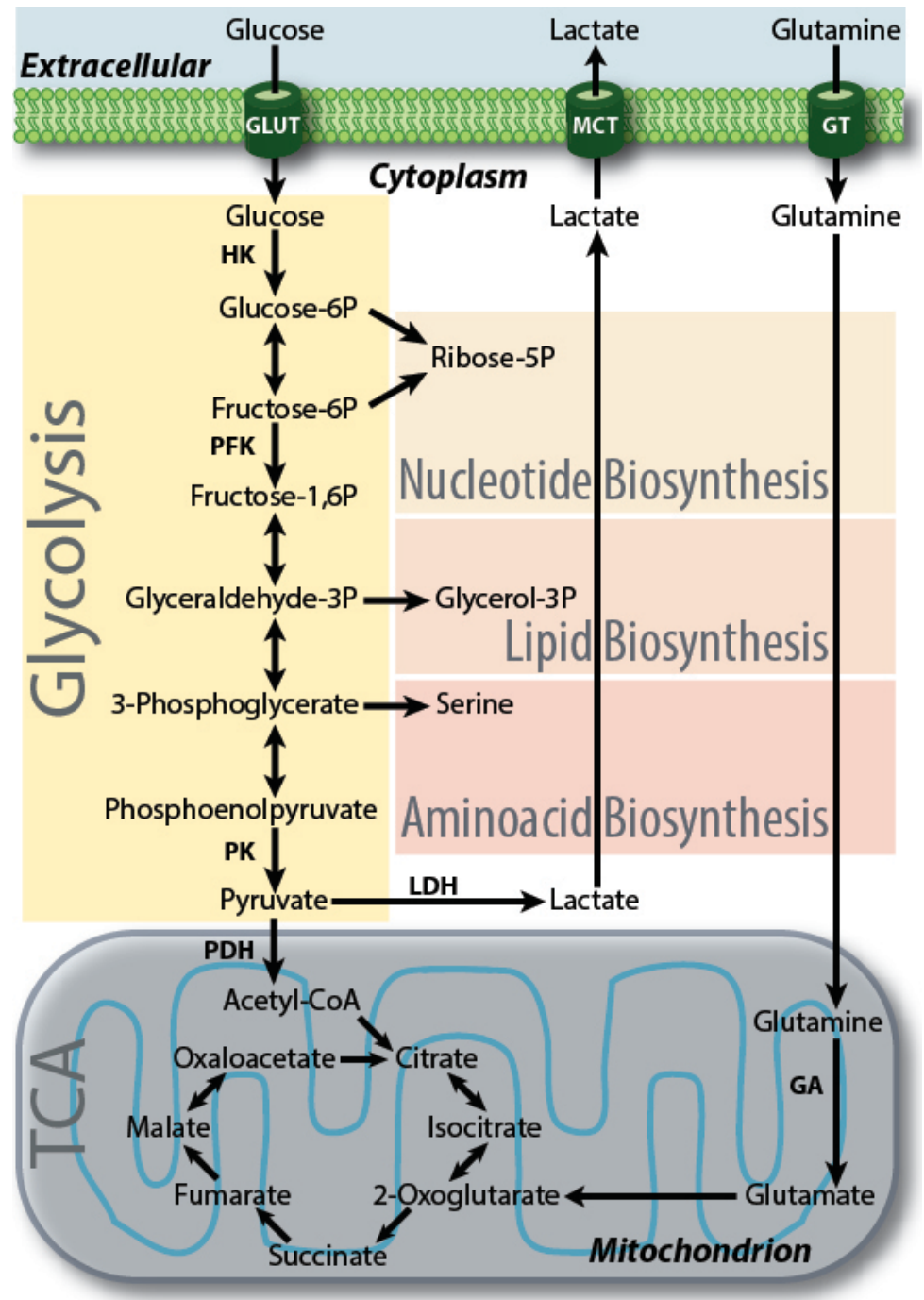

Figure 1: The biochemistry of cancer cell metabolism

Exemplified schematic representation of our current understanding of the biochemical pathways involved in metabolic reprogramming. On entering the cell through GLUTs, glucose is converted to pyruvate by glycolysis. Under normoxic conditions, in normal cells, pyruvate undergoes oxidative phosphorylation in mitochondria, through the TCA cycle. However, upon oxygen deprivation, pyruvate is metabolized to lactate in the cytoplasm. In cancer cells both glycolysis and glutaminolysis are modified. Pyruvate conversion to lactate dominates, even in the presence of oxygen. In parallel, increased glycolysis contributes to anabolic pathways for the production of building materials (such as lipids and amino acids) for the formation of new cells. GLUT, glucose transporter; MCT, monocarboxylate transporter; GT, glutamine transporters; HK, hexokinase; PFK, phosphofructokinase; PK, pyruvate kinase; LDH, lactate dehydrogenase; PDH, pyruvate dehydrogenase; GA, glutaminase. 


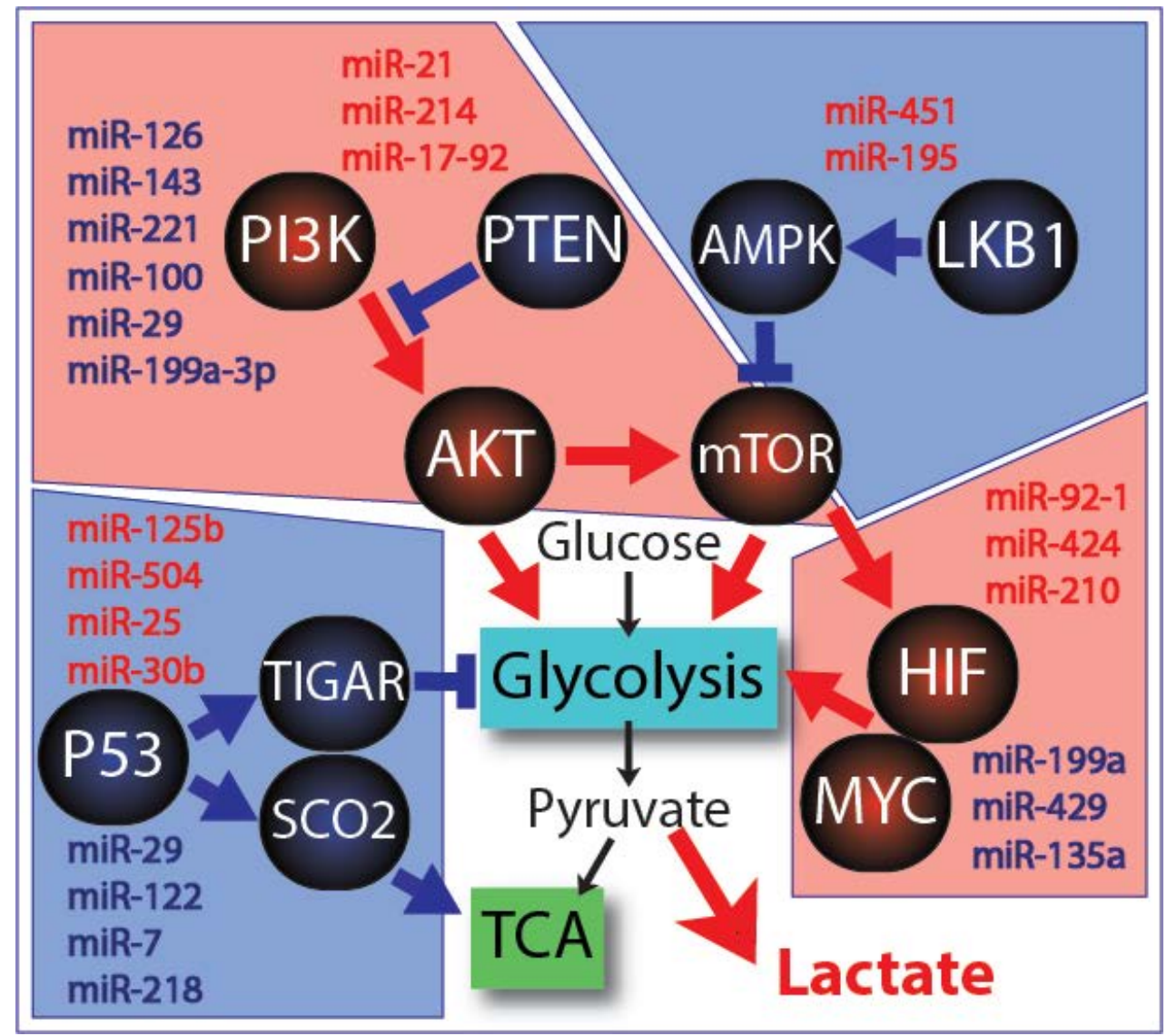

Figure 2: Regulation of signaling pathways involved in cancer metabolism by miRNAs The shift to aerobic glycolysis in cancer cells may be driven or enhanced by miRNAs through the deregulation of signaling pathways and/or transcription factors. AKT activation downstream of PI3K, upregulates several glycolytic enzymes and activates mTOR. In turn, mTOR enhances the activity of HIF. HIF cooperates with MYC in the transcriptional activation of genes encoding glycolytic enzymes. Activation of the PI3K/AKT/mTOR pathway or HIF- and MYC-dependent transcription (red quadrangles) through suppression of inhibitory miRNAs (blue) or upregulation of the oncogenic microRNAs (red), support increased glycolysis and inhibit the TCA cycle. Conversely, LKB1/AMPK signals inhibit mTOR and p53 suppresses glycolysis through TIGAR and increases mitochondrial metabolism through SCO2 (blue quadrangles). Therefore, miRNAs targeting elements of these two pathways, or loss of miRNAs that reinforce them, enhance the glycolytic phenotype. Red and blue indicate molecules and interactions with a positive and negative role in the metabolic reprogramming of cancer cells, respectively. 


\section{References}

1 Cairns, R.A., et al. (2011) Regulation of cancer cell metabolism. Nature reviews. Cancer 11, 8595

2 Vander Heiden, M.G., et al. (2009) Understanding the Warburg effect: the metabolic requirements of cell proliferation. Science 324, 1029-1033

3 Newsholme, E.A., et al. (1985) The role of high rates of glycolysis and glutamine utilization in rapidly dividing cells. Bioscience reports $5,393-400$

4 Jones, R.G. and Thompson, C.B. (2009) Tumor suppressors and cell metabolism: a recipe for cancer growth. Genes \& development 23, 537-548

5 Groves, A.M., et al. (2007) Non-[18F]FDG PET in clinical oncology. The lancet oncology 8, 822830

6 Dang, C.V. (2012) Links between metabolism and cancer. Genes \& development 26, 877-890

7 DeBerardinis, R.J. and Cheng, T. (2010) Q's next: the diverse functions of glutamine in metabolism, cell biology and cancer. Oncogene 29, 313-324

8 Yuneva, M.O., et al. (2012) The metabolic profile of tumors depends on both the responsible genetic lesion and tissue type. Cell metabolism 15, 157-170

9 DeNicola, G.M., et al. (2011) Oncogene-induced Nrf2 transcription promotes ROS detoxification and tumorigenesis. Nature 475, 106-109

10 Iorio, M.V. and Croce, C.M. (2012) microRNA involvement in human cancer. Carcinogenesis 33, 1126-1133

11 Friedman, R.C., et al. (2009) Most mammalian mRNAs are conserved targets of microRNAs. Genome research 19, 92-105

12 Bartel, D.P. (2009) MicroRNAs: target recognition and regulatory functions. Cell 136, 215-233

13 Lee, D. and Shin, C. (2012) MicroRNA-target interactions: new insights from genome-wide approaches. Annals of the New York Academy of Sciences 1271, 118-128

14 Hobert, O. (2008) Gene regulation by transcription factors and microRNAs. Science 319, 17851786

15 Hatziapostolou, M., et al. (2011) An HNF4alpha-miRNA inflammatory feedback circuit regulates hepatocellular oncogenesis. Cell 147, 1233-1247

16 Hatziapostolou, M. and Iliopoulos, D. (2011) Epigenetic aberrations during oncogenesis. Cellular and molecular life sciences : CMLS 68, 1681-1702

17 Rottiers, V. and Naar, A.M. (2012) MicroRNAs in metabolism and metabolic disorders. Nature reviews. Molecular cell biology 13, 239-250

18 Chen, B., et al. (2012) Roles of microRNA on cancer cell metabolism. Journal of translational medicine 10, 228

19 Valeri, N., et al. (2009) Epigenetics, miRNAs, and human cancer: a new chapter in human gene regulation. Mammalian genome : official journal of the International Mammalian Genome Society $20,573-580$

20 Singh, P.K., et al. (2011) Regulation of Aerobic Glycolysis by microRNAs in Cancer. Molecular and cellular pharmacology 3, 125-134

21 Balon, T.W. (2012) SGLT and GLUT: are they teammates? Focus on "Mouse SGLT3a generates proton-activated currents but does not transport sugar". American journal of physiology. Cell physiology 302, C1071-1072

22 Macheda, M.L., et al. (2005) Molecular and cellular regulation of glucose transporter (GLUT) proteins in cancer. Journal of cellular physiology 202, 654-662

23 Fei, X., et al. (2012) MicroRNA-195-5p suppresses glucose uptake and proliferation of human bladder cancer T24 cells by regulating GLUT3 expression. FEBS letters 586, 392-397

24 Shin, D., et al. (2012) miR-32 and its target SLC45A3 regulate the lipid metabolism of oligodendrocytes and myelin. Neuroscience 213, 29-37 
$25 \mathrm{Lu}, \mathrm{H}$., et al. (2010) MicroRNA-223 regulates Glut4 expression and cardiomyocyte glucose metabolism. Cardiovascular research 86, 410-420

26 Horie, T., et al. (2009) MicroRNA-133 regulates the expression of GLUT4 by targeting KLF15 and is involved in metabolic control in cardiac myocytes. Biochemical and biophysical research communications 389, 315-320

27 Raychaudhuri, S. (2012) MicroRNAs overexpressed in growth-restricted rat skeletal muscles regulate the glucose transport in cell culture targeting central TGF-beta factor SMAD4. PloS one 7, e34596

28 Ling, H.Y., et al. (2012) MiRNA-21 reverses high glucose and high insulin induced insulin resistance in 3T3-L1 adipocytes through targeting phosphatase and tensin homologue. Experimental and clinical endocrinology \& diabetes : official journal, German Society of Endocrinology [and] German Diabetes Association 120, 553-559

29 Robey, R.B. and Hay, N. (2006) Mitochondrial hexokinases, novel mediators of the antiapoptotic effects of growth factors and Akt. Oncogene 25, 4683-4696

30 Mathupala, S.P., et al. (2009) Hexokinase-2 bound to mitochondria: cancer's stygian link to the "Warburg Effect" and a pivotal target for effective therapy. Seminars in cancer biology 19, 1724

31 Vander Heiden, M.G., et al. (2011) Metabolic pathway alterations that support cell proliferation. Cold Spring Harbor symposia on quantitative biology 76, 325-334

32 Peschiaroli, A., et al. (2012) miR-143 regulates hexokinase 2 expression in cancer cells. Oncogene

33 Fang, R., et al. (2012) MicroRNA-143 (miR-143) regulates cancer glycolysis via targeting hexokinase 2 gene. The Journal of biological chemistry 287, 23227-23235

34 Gregersen, L.H., et al. (2012) MicroRNA-143 down-regulates Hexokinase 2 in colon cancer cells. BMC cancer 12,232

35 Starczynowski, D.T., et al. (2010) Identification of miR-145 and miR-146a as mediators of the $5 q$ - syndrome phenotype. Nature medicine 16, 49-58

36 Volinia, S., et al. (2010) Reprogramming of miRNA networks in cancer and leukemia. Genome research 20, 589-599

37 Lui, W.O., et al. (2007) Patterns of known and novel small RNAs in human cervical cancer. Cancer research 67, 6031-6043

38 Michael, M.Z., et al. (2003) Reduced accumulation of specific microRNAs in colorectal neoplasia. Molecular cancer research : MCR 1, 882-891

39 Fabani, M.M. and Gait, M.J. (2008) miR-122 targeting with LNA/2'-O-methyl oligonucleotide mixmers, peptide nucleic acids (PNA), and PNA-peptide conjugates. Rna 14, 336-346

40 Ahmad, A., et al. (2011) Phosphoglucose isomerase/autocrine motility factor mediates epithelial-mesenchymal transition regulated by miR-200 in breast cancer cells. Cancer research 71, 3400-3409

41 Mazurek, S., et al. (2005) Pyruvate kinase type M2 and its role in tumor growth and spreading. Seminars in cancer biology 15, 300-308

42 Christofk, H.R., et al. (2008) The M2 splice isoform of pyruvate kinase is important for cancer metabolism and tumour growth. Nature 452, 230-233

43 Kefas, B., et al. (2010) Pyruvate kinase M2 is a target of the tumor-suppressive microRNA326 and regulates the survival of glioma cells. Neuro-oncology 12, 1102-1112

44 Jung, C.J., et al. (2011) Epigenetic modulation of miR-122 facilitates human embryonic stem cell self-renewal and hepatocellular carcinoma proliferation. PloS one 6, e27740

45 Wong, T.S., et al. (2008) Identification of pyruvate kinase type M2 as potential oncoprotein in squamous cell carcinoma of tongue through microRNA profiling. International journal of cancer. Journal international du cancer 123, 251-257

46 Sun, Y., et al. (2012) miR-124, miR-137 and miR-340 regulate colorectal cancer growth via inhibition of the Warburg effect. Oncology reports 28, 1346-1352 
47 Chan, S.Y., et al. (2009) MicroRNA-210 controls mitochondrial metabolism during hypoxia by repressing the iron-sulfur cluster assembly proteins ISCU1/2. Cell metabolism 10, 273-284

48 Kinoshita, T., et al. (2012) Tumor suppressive microRNA-375 regulates lactate dehydrogenase $B$ in maxillary sinus squamous cell carcinoma. International journal of oncology 40, 185-193

49 Isozaki, Y., et al. (2012) Identification of novel molecular targets regulated by tumor suppressive miR-375 induced by histone acetylation in esophageal squamous cell carcinoma. International journal of oncology 41, 985-994

50 Pullen, T.J., et al. (2011) miR-29a and miR-29b contribute to pancreatic beta-cell-specific silencing of monocarboxylate transporter 1 (Mct1). Molecular and cellular biology 31, 3182-3194 $51 \mathrm{Fu}$, T.Y., et al. (2011) Let-7b-mediated suppression of basigin expression and metastasis in mouse melanoma cells. Experimental cell research 317, 445-451

52 Wise, D.R., et al. (2008) Myc regulates a transcriptional program that stimulates mitochondrial glutaminolysis and leads to glutamine addiction. Proceedings of the National Academy of Sciences of the United States of America 105, 18782-18787

$53 \mathrm{Gao}, \mathrm{P}$., et al. (2009) c-Myc suppression of miR-23a/b enhances mitochondrial glutaminase expression and glutamine metabolism. Nature 458, 762-765

54 Dang, C.V. (2010) Glutaminolysis: supplying carbon or nitrogen or both for cancer cells? Cell cycle 9, 3884-3886

55 Vaughn, A.E. and Deshmukh, M. (2008) Glucose metabolism inhibits apoptosis in neurons and cancer cells by redox inactivation of cytochrome c. Nature cell biology 10, 1477-1483

$56 \mathrm{Eng}, \mathrm{C.H}$., et al. (2010) Ammonia derived from glutaminolysis is a diffusible regulator of autophagy. Science signaling 3, ra31

57 Poy, M.N., et al. (2009) miR-375 maintains normal pancreatic alpha- and beta-cell mass. Proceedings of the National Academy of Sciences of the United States of America 106, 58135818

58 Baroukh, N.N. and Van Obberghen, E. (2009) Function of microRNA-375 and microRNA-124a in pancreas and brain. The FEBS journal 276, 6509-6521

59 Plaisance, V., et al. (2006) MicroRNA-9 controls the expression of Granuphilin/SIp4 and the secretory response of insulin-producing cells. The Journal of biological chemistry 281, 2693226942

$60 \mathrm{Zhu}, \mathrm{H}$., et al. (2011) The Lin28/let-7 axis regulates glucose metabolism. Cell 147, 81-94

61 Perez, L.M., et al. (2013) Metabolic rescue of obese adipose-derived stems cells by Lin28/Let7 pathway. Diabetes

$62 \mathrm{He}, \mathrm{A}$., et al. (2007) Overexpression of micro ribonucleic acid 29, highly up-regulated in diabetic rats, leads to insulin resistance in 3T3-L1 adipocytes. Molecular endocrinology 21, 2785-2794

63 Pandey, A.K., et al. (2011) miR-29a levels are elevated in the $\mathrm{db} / \mathrm{db}$ mice liver and its overexpression leads to attenuation of insulin action on PEPCK gene expression in HepG2 cells. Molecular and cellular endocrinology 332, 125-133

64 Ryu, H.S., et al. (2011) The induction of microRNA targeting IRS-1 is involved in the development of insulin resistance under conditions of mitochondrial dysfunction in hepatocytes. PloS one 6, e17343

65 Davalos, A., et al. (2011) miR-33a/b contribute to the regulation of fatty acid metabolism and insulin signaling. Proceedings of the National Academy of Sciences of the United States of America 108, 9232-9237

66 Thomas, M., et al. (2012) The proto-oncogene Pim-1 is a target of miR-33a. Oncogene 31, 918-928

67 Ibrahim, A.F., et al. (2011) MicroRNA replacement therapy for miR-145 and miR-33a is efficacious in a model of colon carcinoma. Cancer research 71, 5214-5224

68 Giles, K.M., et al. (2013) miRNA-7-5p inhibits melanoma cell migration and invasion. Biochemical and biophysical research communications 430, 706-710 
69 Trajkovski, M., et al. (2011) MicroRNAs 103 and 107 regulate insulin sensitivity. Nature 474, 649-653

70 Jordan, S.D., et al. (2011) Obesity-induced overexpression of miRNA-143 inhibits insulinstimulated AKT activation and impairs glucose metabolism. Nature cell biology 13, 434-446

71 Yang, Y.M., et al. (2012) Decrease of microRNA-122 causes hepatic insulin resistance by inducing protein tyrosine phosphatase $1 \mathrm{~B}$, which is reversed by licorice flavonoid. Hepatology 56 , 2209-2220

72 Santos, C.R. and Schulze, A. (2012) Lipid metabolism in cancer. The FEBS journal 279, 26102623

73 Raghow, R., et al. (2008) SREBPs: the crossroads of physiological and pathological lipid homeostasis. Trends in endocrinology and metabolism: TEM 19, 65-73

74 Odom, D.T., et al. (2004) Control of pancreas and liver gene expression by HNF transcription factors. Science 303, 1378-1381

75 Hayhurst, G.P., et al. (2001) Hepatocyte nuclear factor 4alpha (nuclear receptor 2A1) is essential for maintenance of hepatic gene expression and lipid homeostasis. Molecular and cellular biology 21, 1393-1403

76 Gupta, R.K. and Kaestner, K.H. (2004) HNF-4alpha: from MODY to late-onset type 2 diabetes. Trends in molecular medicine 10, 521-524

77 Liu, Y., et al. (2010) Dominant uptake of fatty acid over glucose by prostate cells: a potential new diagnostic and therapeutic approach. Anticancer research 30, 369-374

78 Zha, S., et al. (2005) Peroxisomal branched chain fatty acid beta-oxidation pathway is upregulated in prostate cancer. The Prostate 63, 316-323

79 Rysman, E., et al. (2010) De novo lipogenesis protects cancer cells from free radicals and chemotherapeutics by promoting membrane lipid saturation. Cancer research 70, 8117-8126

80 Lewis, A.P. and Jopling, C.L. (2010) Regulation and biological function of the liver-specific miR-122. Biochemical Society transactions 38, 1553-1557

81 Krutzfeldt, J., et al. (2005) Silencing of microRNAs in vivo with 'antagomirs'. Nature 438, 685689

82 Esau, C., et al. (2006) miR-122 regulation of lipid metabolism revealed by in vivo antisense targeting. Cell metabolism 3, 87-98

83 Elmen, J., et al. (2008) LNA-mediated microRNA silencing in non-human primates. Nature 452, 896-899

$84 \mathrm{Hsu}, \mathrm{S} . \mathrm{H}$., et al. (2012) Essential metabolic, anti-inflammatory, and anti-tumorigenic functions of miR-122 in liver. The Journal of clinical investigation 122, 2871-2883

85 Tsai, W.C., et al. (2012) MicroRNA-122 plays a critical role in liver homeostasis and hepatocarcinogenesis. The Journal of clinical investigation 122, 2884-2897

86 Najafi-Shoushtari, S.H., et al. (2010) MicroRNA-33 and the SREBP host genes cooperate to control cholesterol homeostasis. Science 328, 1566-1569

87 Gerin, I., et al. (2010) Expression of miR-33 from an SREBP2 intron inhibits cholesterol export and fatty acid oxidation. The Journal of biological chemistry 285, 33652-33661

88 Cirera-Salinas, D., et al. (2012) Mir-33 regulates cell proliferation and cell cycle progression. Cell cycle 11, 922-933

89 Esau, C., et al. (2004) MicroRNA-143 regulates adipocyte differentiation. The Journal of biological chemistry $279,52361-52365$

90 Nakanishi, N., et al. (2009) The up-regulation of microRNA-335 is associated with lipid metabolism in liver and white adipose tissue of genetically obese mice. Biochemical and biophysical research communications 385, 492-496

91 Iliopoulos, D., et al. (2010) MicroRNA-370 controls the expression of microRNA-122 and Cpt1alpha and affects lipid metabolism. Journal of lipid research 51, 1513-1523 
92 Rane, S., et al. (2009) Downregulation of miR-199a derepresses hypoxia-inducible factor1alpha and Sirtuin 1 and recapitulates hypoxia preconditioning in cardiac myocytes. Circulation research 104, 879-886

93 Ghosh, A.K., et al. (2009) Aberrant regulation of pVHL levels by microRNA promotes the HIF/VEGF axis in CLL B cells. Blood 113, 5568-5574

94 Ghosh, G., et al. (2010) Hypoxia-induced microRNA-424 expression in human endothelial cells regulates HIF-alpha isoforms and promotes angiogenesis. The Journal of clinical investigation 120, 4141-4154

95 Kelly, T.J., et al. (2011) A hypoxia-induced positive feedback loop promotes hypoxia-inducible factor 1alpha stability through miR-210 suppression of glycerol-3-phosphate dehydrogenase 1like. Molecular and cellular biology 31, 2696-2706

96 Takwi, A.A., et al. (2012) A statin-regulated microRNA represses human c-Myc expression and function. EMBO molecular medicine 4, 896-909

97 O'Donnell, K.A., et al. (2005) c-Myc-regulated microRNAs modulate E2F1 expression. Nature 435, 839-843

98 Olive, V., et al. (2009) miR-19 is a key oncogenic component of mir-17-92. Genes \& development 23, 2839-2849

99 Manning, B.D. and Cantley, L.C. (2007) AKT/PKB signaling: navigating downstream. Cell 129, 1261-1274

100 Miyamoto, S., et al. (2008) Akt mediates mitochondrial protection in cardiomyocytes through phosphorylation of mitochondrial hexokinase-II. Cell death and differentiation 15, 521-529

101 Elstrom, R.L., et al. (2004) Akt stimulates aerobic glycolysis in cancer cells. Cancer research 64, 3892-3899

102 Khatri, S., et al. (2010) FOXO3a regulates glycolysis via transcriptional control of tumor suppressor TSC1. The Journal of biological chemistry 285, 15960-15965

103 Zoncu, R., et al. (2011) mTOR: from growth signal integration to cancer, diabetes and ageing. Nature reviews. Molecular cell biology 12, 21-35

104 Guo, C., et al. (2008) The noncoding RNA, miR-126, suppresses the growth of neoplastic cells by targeting phosphatidylinositol 3-kinase signaling and is frequently lost in colon cancers. Genes, chromosomes \& cancer 47, 939-946

105 Meng, F., et al. (2007) MicroRNA-21 regulates expression of the PTEN tumor suppressor gene in human hepatocellular cancer. Gastroenterology 133, 647-658

106 Polytarchou, C., et al. (2011) Akt2 regulates all Akt isoforms and promotes resistance to hypoxia through induction of miR-21 upon oxygen deprivation. Cancer research 71, 4720-4731

107 Iliopoulos, D., et al. (2009) MicroRNAs differentially regulated by Akt isoforms control EMT and stem cell renewal in cancer cells. Science signaling 2, ra62

108 Pineau, P., et al. (2010) miR-221 overexpression contributes to liver tumorigenesis. Proceedings of the National Academy of Sciences of the United States of America 107, 264-269 109 Nagaraja, A.K., et al. (2010) A link between mir-100 and FRAP1/mTOR in clear cell ovarian cancer. Molecular endocrinology 24, 447-463

110 Fornari, F., et al. (2010) MiR-199a-3p regulates mTOR and c-Met to influence the doxorubicin sensitivity of human hepatocarcinoma cells. Cancer research 70, 5184-5193

111 Hardie, D.G. (2011) AMP-activated protein kinase: an energy sensor that regulates all aspects of cell function. Genes \& development 25, 1895-1908

112 Hezel, A.F. and Bardeesy, N. (2008) LKB1; linking cell structure and tumor suppression. Oncogene 27, 6908-6919

113 Godlewski, J., et al. (2010) MicroRNA-451 regulates LKB1/AMPK signaling and allows adaptation to metabolic stress in glioma cells. Molecular cell 37, 620-632

114 Chen, $\mathrm{H}$., et al. (2012) Micro-RNA-195 and -451 regulate the LKB1/AMPK signaling axis by targeting MO25. PloS one 7, e41574 
115 Mathupala, S.P., et al. (1997) Glucose catabolism in cancer cells. The type II hexokinase promoter contains functionally active response elements for the tumor suppressor p53. The Journal of biological chemistry 272, 22776-22780

116 Bensaad, K., et al. (2006) TIGAR, a p53-inducible regulator of glycolysis and apoptosis. Cell $126,107-120$

117 Stambolic, V., et al. (2001) Regulation of PTEN transcription by p53. Molecular cell 8, 317325

118 Matoba, S., et al. (2006) p53 regulates mitochondrial respiration. Science 312, 1650-1653

119 Le, M.T., et al. (2009) MicroRNA-125b is a novel negative regulator of p53. Genes \& development 23, 862-876

$120 \mathrm{Hu}, \mathrm{W}$., et al. (2010) Negative regulation of tumor suppressor p53 by microRNA miR-504. Molecular cell 38, 689-699

121 Kumar, M., et al. (2011) Negative regulation of the tumor suppressor p53 gene by microRNAs. Oncogene 30, 843-853

122 Park, S.Y., et al. (2009) miR-29 miRNAs activate p53 by targeting p85 alpha and CDC42. Nature structural \& molecular biology 16, 23-29

123 Fornari, F., et al. (2009) MiR-122/cyclin G1 interaction modulates p53 activity and affects doxorubicin sensitivity of human hepatocarcinoma cells. Cancer research 69, 5761-5767

124 Suh, S.S., et al. (2012) MicroRNAs/TP53 feedback circuitry in glioblastoma multiforme. Proceedings of the National Academy of Sciences of the United States of America 109, 53165321

125 Zhang, N., et al. (2012) microRNA-7 is a novel inhibitor of YY1 contributing to colorectal tumorigenesis. Oncogene

$126 \mathrm{He}, \mathrm{X}$., et al. (2012) MicroRNA-218 inhibits cell cycle progression and promotes apoptosis in colon cancer by downregulating oncogene BMI-1. Molecular medicine

127 Sachdeva, M., et al. (2009) p53 represses c-Myc through induction of the tumor suppressor miR-145. Proceedings of the National Academy of Sciences of the United States of America 106, 3207-3212

128 Suzuki, H.I., et al. (2009) Modulation of microRNA processing by p53. Nature 460, 529-533 129 Versteeg, R., et al. (1995) 1p36: every subband a suppressor? European journal of cancer $31 \mathrm{~A}, 538-541$

130 Hermeking, H. (2010) The miR-34 family in cancer and apoptosis. Cell death and differentiation 17, 193-199

$131 \mathrm{He}$, L., et al. (2007) A microRNA component of the p53 tumour suppressor network. Nature 447, 1130-1134

132 Chang, T.C., et al. (2007) Transactivation of miR-34a by p53 broadly influences gene expression and promotes apoptosis. Molecular cell 26, 745-752

133 Raver-Shapira, N., et al. (2007) Transcriptional activation of miR-34a contributes to p53mediated apoptosis. Molecular cell 26, 731-743

134 Concepcion, C.P., et al. (2012) Intact p53-dependent responses in miR-34-deficient mice. PLoS genetics 8, e1002797

135 Sampath, D., et al. (2003) Mechanisms of apoptosis induction by nucleoside analogs. Oncogene 22, 9063-9074

136 Jones, N.P. and Schulze, A. (2012) Targeting cancer metabolism--aiming at a tumour's sweet-spot. Drug discovery today 17, 232-241

137 Vander Heiden, M.G. (2011) Targeting cancer metabolism: a therapeutic window opens. Nature reviews. Drug discovery 10, 671-684

138 Drakaki, A., et al. (2013) Therapeutically Targeting MicroRNAs in Liver Cancer. Current pharmaceutical design 19, 1180-1191

139 Lindow, M. and Kauppinen, S. (2012) Discovering the first microRNA-targeted drug. The Journal of cell biology 199, 407-412 
140 Park, J.K., et al. (2011) miR-221 silencing blocks hepatocellular carcinoma and promotes survival. Cancer research $71,7608-7616$

141 Drakaki, A., et al. (2012) Therapeutically Targeting MicroRNAs in Liver Cancer. Current pharmaceutical design

$142 \mathrm{Kota}, \mathrm{J}$., et al. (2009) Therapeutic microRNA delivery suppresses tumorigenesis in a murine liver cancer model. Cell 137, 1005-1017

143 Trang, P., et al. (2011) Systemic delivery of tumor suppressor microRNA mimics using a neutral lipid emulsion inhibits lung tumors in mice. Molecular therapy : the journal of the American Society of Gene Therapy 19, 1116-1122

144 Del Barco, S., et al. (2011) Metformin: multi-faceted protection against cancer. Oncotarget 2, 896-917

145 Muti, P., et al. (2009) Metformin, diet and breast cancer: an avenue for chemoprevention. Cell cycle 8, 2661

146 Blandino, G., et al. (2012) Metformin elicits anticancer effects through the sequential modulation of DICER and C-MYC. Nature communications 3, 865

147 Iliopoulos, D., et al. (2011) Metformin decreases the dose of chemotherapy for prolonging tumor remission in mouse xenografts involving multiple cancer cell types. Cancer research 71, 3196-3201

148 Hirsch, H.A., et al. (2009) Metformin selectively targets cancer stem cells, and acts together with chemotherapy to block tumor growth and prolong remission. Cancer research 69, 7507-7511 149 Hirsch, H.A., et al. (2013) Metformin inhibits the inflammatory response associated with cellular transformation and cancer stem cell growth. Proceedings of the National Academy of Sciences of the United States of America 110, 972-977

150 Zhao, Y., et al. (2013) microRNA response elements-regulated TRAIL expression shows specific survival-suppressing activity on bladder cancer. Journal of experimental \& clinical cancer research : CR 32, 10

151 Szafranska, A.E., et al. (2007) MicroRNA expression alterations are linked to tumorigenesis and non-neoplastic processes in pancreatic ductal adenocarcinoma. Oncogene 26, 4442-4452

152 Moriya, Y., et al. (2012) Tumor suppressive microRNA-133a regulates novel molecular networks in lung squamous cell carcinoma. Journal of human genetics 57, 38-45

153 Mathe, E.A., et al. (2009) MicroRNA expression in squamous cell carcinoma and adenocarcinoma of the esophagus: associations with survival. Clinical cancer research : an official journal of the American Association for Cancer Research 15, 6192-6200

154 Earle, J.S., et al. (2010) Association of microRNA expression with microsatellite instability status in colorectal adenocarcinoma. The Journal of molecular diagnostics : JMD 12, 433-440 $155 \mathrm{Li}$, J., et al. (2012) MicroRNA-223 functions as an oncogene in human gastric cancer by targeting FBXW7/hCdc4. Journal of cancer research and clinical oncology 138, 763-774

156 Laios, A., et al. (2008) Potential role of miR-9 and miR-223 in recurrent ovarian cancer. Molecular cancer 7, 35

157 Mascaux, C., et al. (2009) Evolution of microRNA expression during human bronchial squamous carcinogenesis. The European respiratory journal : official journal of the European Society for Clinical Respiratory Physiology 33, 352-359

158 Dacic, S., et al. (2010) miRNA expression profiling of lung adenocarcinomas: correlation with mutational status. Modern pathology : an official journal of the United States and Canadian Academy of Pathology, Inc 23, 1577-1582

159 Gorur, A., et al. (2012) Determination of plasma microRNA for early detection of gastric cancer. Molecular biology reports

160 Wang, X., et al. (2012) Downregulation of miR-195 correlates with lymph node metastasis and poor prognosis in colorectal cancer. Medical oncology 29, 919-927 
161 Lakomy, R., et al. (2011) MiR-195, miR-196b, miR-181c, miR-21 expression levels and O-6methylguanine-DNA methyltransferase methylation status are associated with clinical outcome in glioblastoma patients. Cancer science 102, 2186-2190

162 Ozata, D.M., et al. (2011) The role of microRNA deregulation in the pathogenesis of adrenocortical carcinoma. Endocrine-related cancer 18, 643-655

163 Piepoli, A., et al. (2012) Mirna expression profiles identify drivers in colorectal and pancreatic cancers. PloS one 7, e33663

164 Jahid, S., et al. (2012) miR-23a promotes the transition from indolent to invasive colorectal cancer. Cancer discovery 2, 540-553

165 Wang, B., et al. (2012) Stat3-mediated activation of microRNA-23a suppresses gluconeogenesis in hepatocellular carcinoma by down-regulating glucose-6-phosphatase and peroxisome proliferator-activated receptor gamma, coactivator 1 alpha. Hepatology 56, 186-197 166 Scapoli, L., et al. (2010) MicroRNA expression profiling of oral carcinoma identifies new markers of tumor progression. International journal of immunopathology and pharmacology 23, 1229-1234

167 Gottardo, F., et al. (2007) Micro-RNA profiling in kidney and bladder cancers. Urologic oncology 25, 387-392

$168 \mathrm{Wu}$, B.L., et al. (2011) MiRNA profile in esophageal squamous cell carcinoma: downregulation of miR-143 and miR-145. World journal of gastroenterology : WJG 17, 79-88

169 Pagliuca, A., et al. (2012) Analysis of the combined action of miR-143 and miR-145 on oncogenic pathways in colorectal cancer cells reveals a coordinate program of gene repression. Oncogene

170 Liu, L., et al. (2012) miR-143 is downregulated in cervical cancer and promotes apoptosis and inhibits tumor formation by targeting $\mathrm{Bcl}-2$. Molecular medicine reports 5, 753-760

171 Ugras, S., et al. (2011) Small RNA sequencing and functional characterization reveals MicroRNA-143 tumor suppressor activity in liposarcoma. Cancer research 71, 5659-5669

172 Han, Y., et al. (2011) MicroRNA expression signatures of bladder cancer revealed by deep sequencing. PloS one 6 , e18286

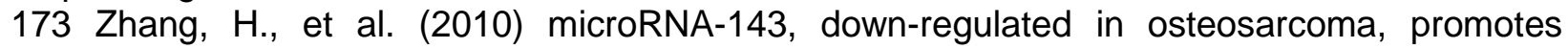
apoptosis and suppresses tumorigenicity by targeting Bcl-2. Oncology reports 24, 1363-1369

174 Takagi, T., et al. (2009) Decreased expression of microRNA-143 and -145 in human gastric cancers. Oncology $77,12-21$

175 Liu, X., et al. (2012) MiR-138 suppressed nasopharyngeal carcinoma growth and tumorigenesis by targeting the CCND1 oncogene. Cell cycle 11, 2495-2506

176 Wang, W., et al. (2012) MiR-138 induces cell cycle arrest by targeting cyclin D3 in hepatocellular carcinoma. Carcinogenesis 33, 1113-1120

177 Yip, L., et al. (2011) MicroRNA signature distinguishes the degree of aggressiveness of papillary thyroid carcinoma. Annals of surgical oncology 18, 2035-2041

178 Wong, T.S., et al. (2008) Mature miR-184 as Potential Oncogenic microRNA of Squamous Cell Carcinoma of Tongue. Clinical cancer research : an official journal of the American Association for Cancer Research 14, 2588-2592

179 Liu, X., et al. (2009) MicroRNA profiling and head and neck cancer. Comparative and functional genomics, 837514

180 Zeng, C., et al. (2010) A novel GSK-3 beta-C/EBP alpha-miR-122-insulin-like growth factor 1 receptor regulatory circuitry in human hepatocellular carcinoma. Hepatology 52, 1702-1712 181 Karakatsanis, A., et al. (2011) Expression of microRNAs, miR-21, miR-31, miR-122, miR145, miR-146a, miR-200c, miR-221, miR-222, and miR-223 in patients with hepatocellular carcinoma or intrahepatic cholangiocarcinoma and its prognostic significance. Molecular carcinogenesis 
182 D'Angelo, D., et al. (2012) Altered microRNA expression profile in human pituitary GH adenomas: down-regulation of miRNA targeting HMGA1, HMGA2, and E2F1. The Journal of clinical endocrinology and metabolism 97, E1128-1138

183 Vosa, U., et al. (2012) Meta-analysis of microRNA expression in lung cancer. International journal of cancer. Journal international du cancer

184 Juan, D., et al. (2010) Identification of a microRNA panel for clear-cell kidney cancer. Urology $75,835-841$

185 Papaconstantinou, I.G., et al. (2013) Expression of microRNAs in patients with pancreatic cancer and its prognostic significance. Pancreas 42, 67-71

186 Hong, L., et al. (2012) High expression of miR-210 predicts poor survival in patients with breast cancer: a meta-analysis. Gene 507, 135-138

187 Nohata, N., et al. (2011) Tumor suppressive microRNA-375 regulates oncogene AEG1/MTDH in head and neck squamous cell carcinoma (HNSCC). Journal of human genetics 56 , 595-601

188 Friboulet, L., et al. (2011) Molecular Characteristics of ERCC1-Negative versus ERCC1Positive Tumors in Resected NSCLC. Clinical cancer research : an official journal of the American Association for Cancer Research 17, 5562-5572

189 Gaedcke, J., et al. (2012) The rectal cancer microRNAome--microRNA expression in rectal cancer and matched normal mucosa. Clinical cancer research : an official journal of the American Association for Cancer Research 18, 4919-4930

190 Chen, Z., et al. (2013) Gastric adenocarcinoma has a unique microRNA signature not present in esophageal adenocarcinoma. Cancer

191 Zhao, J.J., et al. (2010) microRNA expression profile and identification of miR-29 as a prognostic marker and pathogenetic factor by targeting CDK6 in mantle cell lymphoma. Blood $115,2630-2639$

192 Wang, X.S., et al. (2012) MicroRNA-29a and microRNA-142-3p are regulators of myeloid differentiation and acute myeloid leukemia. Blood 119, 4992-5004

193 Zhu, X.C., et al. (2012) microRNA-29a suppresses cell proliferation by targeting SPARC in hepatocellular carcinoma. International journal of molecular medicine 30, 1321-1326

194 Nguyen, T., et al. (2011) Downregulation of microRNA-29c is associated with hypermethylation of tumor-related genes and disease outcome in cutaneous melanoma. Epigenetics : official journal of the DNA Methylation Society 6, 388-394

$195 \mathrm{Xia}, \mathrm{J}$. , et al. (2012) miR-124 inhibits cell proliferation in gastric cancer through downregulation of SPHK1. The Journal of pathology 227, 470-480

196 Wang, P., et al. (2013) Methylation-mediated silencing of the miR-124 genes facilitates pancreatic cancer progression and metastasis by targeting Rac1. Oncogene

197 Wang, M.J., et al. (2013) Downregulation of microRNA-124 is an independent prognostic factor in patients with colorectal cancer. International journal of colorectal disease 28, 183-189

198 Wong, K.Y., et al. (2011) Epigenetic inactivation of the miR-124-1 in haematological malignancies. PloS one 6, e19027

199 Wilting, S.M., et al. (2010) Methylation-mediated silencing and tumour suppressive function of hsa-miR-124 in cervical cancer. Molecular cancer 9, 167

$200 \mathrm{Li}, \mathrm{K} . \mathrm{K}$., et al. (2009) miR-124 is frequently down-regulated in medulloblastoma and is a negative regulator of SLC16A1. Human pathology 40, 1234-1243

201 Quesne, J.L., et al. (2012) Biological and prognostic associations of miR-205 and let-7b in breast cancer revealed by in situ hybridization analysis of micro-RNA expression in arrays of archival tumour tissue. The Journal of pathology 227, 306-314

202 Nam, E.J., et al. (2008) MicroRNA expression profiles in serous ovarian carcinoma. Clinical cancer research : an official journal of the American Association for Cancer Research 14, 26902695 
203 Jakymiw, A., et al. (2010) Overexpression of dicer as a result of reduced let-7 MicroRNA levels contributes to increased cell proliferation of oral cancer cells. Genes, chromosomes \& cancer $49,549-559$

204 Duan, Z., et al. (2011) MicroRNA-199a-3p is downregulated in human osteosarcoma and regulates cell proliferation and migration. Molecular cancer therapeutics 10, 1337-1345

205 Huang, L., et al. (2012) Downregulation of six microRNAs is associated with advanced stage, lymph node metastasis and poor prognosis in small cell carcinoma of the cervix. PloS one 7, e33762

206 Cheung, H.H., et al. (2010) Genome-wide DNA methylation profiling reveals novel epigenetically regulated genes and non-coding RNAs in human testicular cancer. British journal of cancer 102, 419-427

$207 \mathrm{Hou}$, J., et al. (2011) Identification of miRNomes in human liver and hepatocellular carcinoma reveals miR-199a/b-3p as therapeutic target for hepatocellular carcinoma. Cancer cell 19, 232243

208 Iorio, M.V., et al. (2007) MicroRNA signatures in human ovarian cancer. Cancer research 67, 8699-8707

209 Gao, X., et al. (2012) MiR-15a, miR-16-1 and miR-17-92 cluster expression are linked to poor prognosis in multiple myeloma. Leukemia research 36, 1505-1509

210 Hayashita, Y., et al. (2005) A polycistronic microRNA cluster, miR-17-92, is overexpressed in human lung cancers and enhances cell proliferation. Cancer research 65, 9628-9632

211 Guo, S.T., et al. (2012) MicroRNA-497 targets insulin-like growth factor 1 receptor and has a tumour suppressive role in human colorectal cancer. Oncogene

212 Hidaka, H., et al. (2012) Tumor suppressive microRNA-1285 regulates novel molecular targets: aberrant expression and functional significance in renal cell carcinoma. Oncotarget 3, 4457

213 Sun, T., et al. (2011) miR-429 modulates the expression of c-myc in human gastric carcinoma cells. European journal of cancer 47, 2552-2559

214 Luo, Z., et al. (2012) An in silico analysis of dynamic changes in microRNA expression profiles in stepwise development of nasopharyngeal carcinoma. BMC medical genomics 5, 3

$215 \mathrm{Wu}, \mathrm{H}$., et al. (2012) MiR-135a targets JAK2 and inhibits gastric cancer cell proliferation. Cancer biology \& therapy $13,281-288$

$216 \mathrm{Wu}, \mathrm{S}$., et al. (2012) MiR-135a functions as a selective killer of malignant glioma. Oncogene 31, 3866-3874

217 Navarro, A., et al. (2009) Regulation of JAK2 by miR-135a: prognostic impact in classic Hodgkin lymphoma. Blood 114, 2945-2951

218 Hamada, S., et al. (2012) MiR-126 acts as a tumor suppressor in pancreatic cancer cells via the regulation of ADAM9. Molecular cancer research : MCR 10, 3-10

219 Santarelli, L., et al. (2011) Association of MiR-126 with soluble mesothelin-related peptides, a marker for malignant mesothelioma. PloS one 6, e18232

220 Zhang, Y., et al. (2013) miR-126 and miR-126(*) repress recruitment of mesenchymal stem cells and inflammatory monocytes to inhibit breast cancer metastasis. Nature cell biology $15,284-$ 294

221 Feng, R., et al. (2010) miR-126 functions as a tumour suppressor in human gastric cancer. Cancer letters 298, 50-63

222 Wang, X., et al. (2008) Aberrant expression of oncogenic and tumor-suppressive microRNAs in cervical cancer is required for cancer cell growth. PloS one 3, e2557

223 Farazi, T.A., et al. (2011) MicroRNA sequence and expression analysis in breast tumors by deep sequencing. Cancer research 71, 4443-4453

224 Chan, J.A., et al. (2005) MicroRNA-21 is an antiapoptotic factor in human glioblastoma cells. Cancer research 65, 6029-6033 
225 Fulci, V., et al. (2007) Quantitative technologies establish a novel microRNA profile of chronic lymphocytic leukemia. Blood 109, 4944-4951

226 Zhang, Z., et al. (2008) miR-21 plays a pivotal role in gastric cancer pathogenesis and progression. Laboratory investigation; a journal of technical methods and pathology 88, 13581366

$227 \mathrm{Xu}, \mathrm{X} . \mathrm{M}$., et al. (2012) Expression of miR-21, miR-31, miR-96 and miR-135b is correlated with the clinical parameters of colorectal cancer. Oncology letters 4, 339-345

228 Volinia, S., et al. (2006) A microRNA expression signature of human solid tumors defines cancer gene targets. Proceedings of the National Academy of Sciences of the United States of America 103, 2257-2261

229 Feber, A., et al. (2008) MicroRNA expression profiles of esophageal cancer. The Journal of thoracic and cardiovascular surgery 135, 255-260; discussion 260

230 Liu, J., et al. (2012) MicroRNA-100 is a potential molecular marker of non-small cell lung cancer and functions as a tumor suppressor by targeting polo-like kinase 1 . BMC cancer 12, 519 231 Sun, J., et al. (2013) MicroRNA-99a/100 promotes apoptosis by targeting mTOR in human esophageal squamous cell carcinoma. Medical oncology 30, 411

232 Chen, Z., et al. (2012) Down-regulation of the microRNA-99 family members in head and neck squamous cell carcinoma. Oral oncology 48, 686-691

$233 \mathrm{Li}, \mathrm{B} . \mathrm{H}$., et al. (2011) Reduced miR-100 expression in cervical cancer and precursors and its carcinogenic effect through targeting PLK1 protein. European journal of cancer 47, 2166-2174

234 Xu, C., et al. (2013) miRNA-100 Inhibits Human Bladder Urothelial Carcinogenesis by Directly Targeting mTOR. Molecular cancer therapeutics 12, 207-219

235 Ali, S., et al. (2012) MicroRNA profiling of diagnostic needle aspirates from patients with pancreatic cancer. British journal of cancer 107, 1354-1360

236 Tian, Y., et al. (2012) MicroRNA miR-451 downregulates the PI3K/AKT pathway through CAB39 in human glioma. International journal of oncology 40, 1105-1112

237 Hui, A.B., et al. (2010) Comprehensive MicroRNA profiling for head and neck squamous cell carcinomas. Clinical cancer research : an official journal of the American Association for Cancer Research 16, 1129-1139

238 Zanette, D.L., et al. (2007) miRNA expression profiles in chronic lymphocytic and acute lymphocytic leukemia. Brazilian journal of medical and biological research = Revista brasileira de pesquisas medicas e biologicas / Sociedade Brasileira de Biofisica ... [et al.] 40, 1435-1440

239 Guo, J., et al. (2009) Differential expression of microRNA species in human gastric cancer versus non-tumorous tissues. Journal of gastroenterology and hepatology 24, 652-657

240 Jiang, F., et al. (2011) MiR-125b promotes proliferation and migration of type II endometrial carcinoma cells through targeting TP53INP1 tumor suppressor in vitro and in vivo. BMC cancer 11,425

$241 \mathrm{Li}, \mathrm{W}$., et al. (2008) Diagnostic and prognostic implications of microRNAs in human hepatocellular carcinoma. International journal of cancer. Journal international du cancer 123, 1616-1622

242 Vriens, M.R., et al. (2012) MicroRNA expression profiling is a potential diagnostic tool for thyroid cancer. Cancer 118, 3426-3432

243 Chapiro, E., et al. (2010) A new recurrent translocation t(11;14)(q24;q32) involving IGH@ and miR-125b-1 in B-cell progenitor acute lymphoblastic leukemia. Leukemia 24, 1362-1364

244 Kong, X., et al. (2012) MicroRNA-7 inhibits epithelial-to-mesenchymal transition and metastasis of breast cancer cells via targeting FAK expression. PloS one 7, e41523

245 Kong, D., et al. (2012) Inflammation-induced repression of tumor suppressor miR-7 in gastric tumor cells. Oncogene 31, 3949-3960

246 Kefas, B., et al. (2008) microRNA-7 inhibits the epidermal growth factor receptor and the Akt pathway and is down-regulated in glioblastoma. Cancer research 68, 3566-3572 
247 Gao, C., et al. (2010) Reduced microRNA-218 expression is associated with high nuclear factor kappa $B$ activation in gastric cancer. Cancer 116, 41-49

248 Yamamoto, N., et al. (2013) Tumor suppressive microRNA-218 inhibits cancer cell migration and invasion by targeting focal adhesion pathways in cervical squamous cell carcinoma. International journal of oncology

249 Davidson, M.R., et al. (2010) MicroRNA-218 is deleted and downregulated in lung squamous cell carcinoma. PloS one 5, e12560

250 Venkataraman, S., et al. (2013) MicroRNA 218 acts as a tumor suppressor by targeting multiple cancer phenotype-associated genes in medulloblastoma. The Journal of biological chemistry 288, 1918-1928

251 Warburg, O. (1956) On respiratory impairment in cancer cells. Science 124, 269-270

252 Warburg, O. (1956) On the origin of cancer cells. Science 123, 309-314

253 Hamanaka, R.B. and Chandel, N.S. (2012) Targeting glucose metabolism for cancer therapy. The Journal of experimental medicine 209, 211-215

254 Lopez-Rios, F., et al. (2007) Loss of the mitochondrial bioenergetic capacity underlies the glucose avidity of carcinomas. Cancer research 67, 9013-9017

255 Ruby, J.G., et al. (2007) Intronic microRNA precursors that bypass Drosha processing. Nature 448, 83-86

256 Lee, Y., et al. (2003) The nuclear RNase III Drosha initiates microRNA processing. Nature 425, 415-419

$257 \mathrm{Yi}, \mathrm{R}$., et al. (2003) Exportin-5 mediates the nuclear export of pre-microRNAs and short hairpin RNAs. Genes \& development 17, 3011-3016

258 Ketting, R.F., et al. (2001) Dicer functions in RNA interference and in synthesis of small RNA involved in developmental timing in C. elegans. Genes \& development 15, 2654-2659

259 Hutvagner, G., et al. (2001) A cellular function for the RNA-interference enzyme Dicer in the maturation of the let-7 small temporal RNA. Science 293, 834-838

260 Gregory, R.I., et al. (2005) Human RISC couples microRNA biogenesis and posttranscriptional gene silencing. Cell 123, 631-640

261 Khvorova, A., et al. (2003) Functional siRNAs and miRNAs exhibit strand bias. Cell 115, 209216 